\title{
Leucoplasia pilosa: revisão da literatura e apresentação de um caso $\left({ }^{*}\right)$ Hairy leukoplakia: review of the literature and report of a case
}

\author{
Marcos Martins Neto* \\ Pantelis Varvaki Rados ${ }^{\star \star}$ \\ João Jorge Diniz Barbachan**
}

\begin{abstract}
RESUMO
Os autores têm o objetivo de apresentar um caso de leucoplasia pilosa relacionada à paciente portador do vírus HIV. Serão abordados os aspectos clinico, histopatológico e formulação do diagnóstico, além de enfatizar-se o papel do cirurgião-dentista no diagnóstico das manifestações bucais da AIDS.

SUMMARY

The autors present a report of a case of about hairy leukoplakia that have relationship with a HIV seropositive patient. We will discuss the clinical and histopathological aspects of these lesions. It is stressed the role of the dentist in the of AIDS related oral lesions.
\end{abstract}

\section{UNITERMOS}

Leucoplasia Pilosa, Virus EBV, Virus HIV, AIDS

\section{KEYWORDS}

Hairy Leukoplakia, EBV virus HIV virus, AIDS

\section{Introdução}

A leucoplasia pilosa, segundo Axell e col${ }^{2}$ é classificada como uma lesão esbranquiçada ou acinzentada, localizada nas bordas laterais da língua, não sendo removiveis por raspagem, podendo apresentar enrrugamentos verticais. Estende-se para a superficie ventral e dorsal da língua. Atualmente, esta lesão está relacionada às manifestaçōes bucais da AIDS (Sindrome da Imunodeficiência Adquirida) $2^{2,3,5,6,7,89,10,12,13,14,16,17,19}$. A lesāo foi descrita pela primeira vez por Greenspan e $\mathrm{col}^{7} \mathrm{em}$ 1984, após um estudo feito em homossexuais masculinos jovens, em São Francisco - EUA. Pindborg ${ }^{12}$ atribui mais de 40 tipos de lesões bucais, associadas à infecção pelo virus HIV sendo que para Itin e $\mathrm{col}^{9}$ aproximadamente $10 \%$ da populaçăo infectada pelo HIV terá na cavidade bucal o primeiro sinal desta doença. Dutra e $\mathrm{Col}^{3}$, em 1993, realizaram um estudo em 50 pacientes aidéticos de uma unidade do sistema prisional da Grande São Paulo, onde verificaram o ressecamento do lábio inferior, hiperemia de orofaringe, gengivite úlceronecrosante aguda (GUNA), leucoplasia pilosa, leucoplasia jugal, periodontite, lesões do palato e candidíase eram as principais alteraçöes bucais. Naquele trabalho a prevalência da leucoplasia pilosa atingiu o indice de $80 \%$. A leucoplasia pilosa é considerada um indicativo da manifestação da AIDS em cerca de 3 anos $^{17}$. Ramirez e colli3 no ano de 1992 relataram que a leucoplasia pilosa e a candidiase eritematosa foram as lesōes bucais mais frequentes, com indices de 40 e $31 \%$, respectivamente, em pacientes HIV - positivos.

A etiopatogenia desta lesão está relacionada com uma infecção oportunista ocasionada pelo virus Epstein-Barr (EBV) ${ }^{14}$. Sciubba et al $^{16}$ relataram que o EBV è um agente infecci- oso oportunista nas lesões de leucoplasia pilosa, o que não acontece com o HIV e o virus do papiloma humano (HPV). Näher et $a l^{11} \mathrm{e}$ Schmidt - Westhausen ${ }^{15}$ descreveram que o EBV pode ser identificado nas bordas laterais da lingua durante uma grave imunodepressão, mesmo antes da manifestaçăo clínica da leucoplasia pilosa.

Estudos sorológicos, imunohistoquimicos e hibridização do ácido desoxirribonucleico (DNA) indicam que o virus Epstein-Barr (EBV) pode desempenhar um papel no desenvolvimento da lesão $0^{5,6,7,18}$. Porém, tanto na mucosa oral normal como nas lesões de pacientes HIV - positivos poderão ser identificadas formas latentes do EBV ${ }^{1,18}$

Clinicamente, a leucoplasia pilosa pode ser variável, tendo sido relatado o aparecimento bilateral ${ }^{13}$. Caracteriza-se por uma superficie de contorno irregular, frequentemente corrugada ou pregueada, podendo também apresentar-se lisa com aspecto macular. A maioria dos casos relatados mostra que as lesōes localizam-se ao longo das bordas laterais da língua, podendo estender-se para a superficie dorsal. Raramente atingem a mucosa jugal, palato ou soalho da boca. Usualmente säo assintomáticas, embora uma superinfecção pela candida possa causar algum desconforto. Em casos em que todo o dorso da língua é envolvido pelo processo, o paciente pode notar a lesão e consultar o cirurgiāo-dentista $2,3,13,14,17$.

Microscopicamente a lesão apresenta-se como uma hiperplasia epitelial com acantose, paraceratose e projeções epiteliais com aparência de fio de cabelo, com discreto ou nenhum infiltrado inflamatório, múltiplas células vacuolizadas (coilócitos) associadas com a infecção pelo virus Epstein-Barr (EBV) ${ }^{8,9,14}$. Segundo Regezi e Sciubba ${ }^{14}$, as camadas superficiais da lesão apresentam hiperparaceratose acentuada, na maioria dos casos com a formação de irregularidades $e$ cristas ceratóticas na superficie. Muitas vezes, notam-se hifas de Candida albicans estendendo-se para as camadas superficiais das células epiteliais. Na camada de células espinhosas observa-se a coilocitose, que è a degeneração em balão e halo claro perinuclear. Silverman $\mathrm{Jr} .{ }^{19}$ descreveu que os coilócitos são células infectadas por agentes virais.

Diversos autores afirmam que o tratamento da leucoplasia pilosa é controverso $0^{9,14,19}$. Segundo Itin ${ }^{9}$, o tratamento se baseia no uso de medicação antifúngica, azidotimidina(AZT), podofilina ou excisão cirúrgica. Silverman Jr. ${ }^{19}$ relata que o tratamento da leucoplasia pilosa é opcional e sugere que esta pode desaparecer após altas doses de acyclovir, solução tópica de Regin-A e uso de antibióticos tipo sulfa administrada para o controle da pneumonia por pneumocistys. Porém, Greenspan \& Greenspan ${ }^{8}$ afirmam que alesão pode recidivar caso a terapia seja modificada, cessada ou descontinuada.

\section{Apresentação de caso}

Paciente do sexo masculino, cor branca, casado, 35 anos, professor, estava em tratamento na Clinica de Prótese da FO-UFRGS, para confecção de elemento de prótese fixa

(+) Este trabalho foi parcialmente apresentado no 11 Congresso da Sociedade Brasileira de Estomatologia (SOBE), realizado de 12 à 16 de Jutho de 1994 em Goiânia-GO.

* Professordo Departamento de Patologia-UFSM, aluno do Curso de Mestrado em Patologia Bucal - FO-UFRGS.

* Professor do Curso de Mestrado em Patologia Bucal - FO-UFRGS. 
unitária ao nivel do segundo pré-molar inferior direito. Durante os procedimentos clínicos, foi observada uma mancha branca na borda da lingua, lado direito (Fig. 1). O paciente foi então encaminhado à Disciplina de Patologia da mesma faculdade onde também foram observadas manchas semelhantes na borda lateral esquerda (Fig. 2).

Após o exame clínico, decidiu-se que o paciente seria submetido a uma biópsia de ambas lesōes além da solicitação do teste anti-HIV (Elisa), pois nesse momento as informações clinicas sugeriam a leucoplasia pilo$\mathrm{sa}$. As peças cirúrgicas foram encaminhadas para exame histopatológico, que mostraram hiperplasia epitelial com acantose hiperparaceratose e coilocitose. O tecido conjuntivo apresentou um discreto infiltrado inflamatório crônico (Fig. 3). Notou-se a presença de hifas de candida associadas às porçōes mais superficiais do epitélio nos cortes corados pelo P.A.S. (Ácido Periódico de Schiff) (Fig. 4) A sorologia foi positiva para o HIV, sendo mais tarde confirmada pelo exame Western-blot.

Tendo em vista as caracteristicas clínicas e os resultados dos vários exames complementares, confirmou-se o diagnóstico final de leucoplasia pilosa, neste caso associada a imunodepressão provocada pela infecção por HIV.

\section{Discussão}

No que diz respeito aos aspectos clinicos e histopatológicos nossos achados concordam com os relatos de diversos autores $^{2,7,9,14,17,19}$, ou seja, estas lesōes possuem coloração esbranquiçada ou acinzentada, năo são removiveis e podem ser bilaterais, tem localização preferencial na borda de língua podendo estender-se para a superficie ventral e dorsal (Figs, 1 e 2). Os aspectos histológicos revelam hiperparaqueratose acentuada muitas vezes, formando irregularidades e cristas ceratóticas na superfície. Verifica-se degeneraçāo em balão e halo claro perinuclear (coilocitose) na camada de células espinhosas e pode-se observar hifas de Candida albicans nas camadas superficiais do epitélio, fatos relatados pela maioria dos autores $s^{7,10,14,19}$ vistos também neste caso (Figs. 3 e 4 )

Ao que se refere ao diagnóstico da leucoplasia pilosa, vários autores preconizam a necessidade da demonstração do virus EBV nas lesões $2,4,8,10,14$. Segundo Greenspan \& Greenspan ${ }^{8}$ este virus pode ser demonstrado por microscopia eletrônica, antigenos virais ou imunocitoquimica. Entretanto, nossa conduta na formulação do diagnóstico de leucoplasia pilosa baseou-se nos achados clinicos elaboratoriais (teste anti-HIV, Westernblot, histopatologia convencional) associados a um estado de imunodepressāo em paciente portador do virus HIV.

Considerando que a leucoplasia pilosa é uma das manifestações mais frequentes da AIDS na boca, o cirurgião-dentista possui um papel importante no diagnóstico desta lesăo. No caso relatado, convém frizar que o paciente desconhecia que era portador do virus HIV. sendo a partir do diagnóstico clínico da leucoplasia pilosa na lingua que sugeriu-se o teste anti-HIV, o qual foi positivo e posteriormente confirmado pelo Western-blot.

Após a formulação do diagnóstico, o paciente foi encaminhado para a Unidade de Estomatologia do Serviço de Otorrinolaringoloria do Hospital de Clinicas de Porto Alegre (HCPA) para avaliação e acompanhamento.

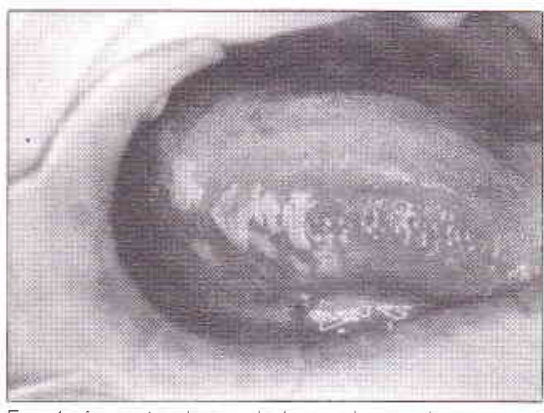

borda lateral direla da lingua

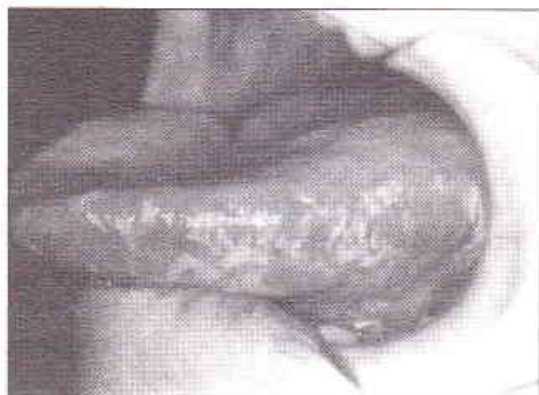

Fig 2 Manchas esbranquiçadas na borda lateral esquerda da lingua, com aspeclo clinico sugestivo de leucoplasia pilosa

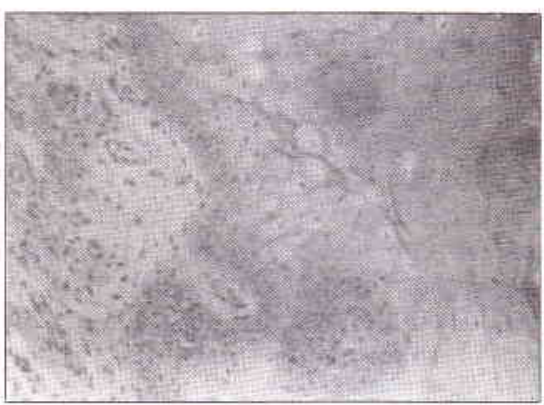

Fig 3 Aspecto microscópico da lesāo mostrando hiperparaceralose, acanlose e coilocitose na camada de células espinhosas, no tecido conjuntivo se vê discreto infiltrado inflamatório mononuclear (Aumento aproximado 400x, H/E)

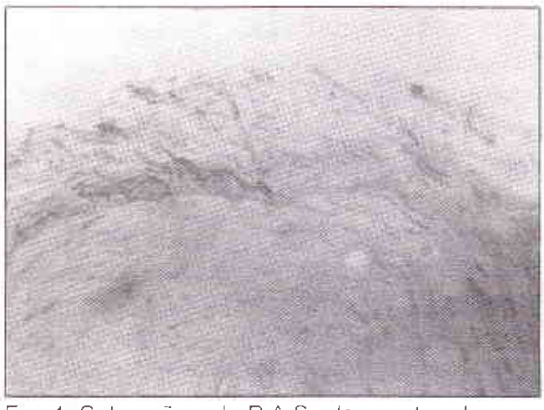

Fig 4 Coloraçäo pelo PAS, demonstrando as hifas de Candida albicans nas camadas mais superficiais do tecido epitelial

\section{Referências Bibliográficas}

1. ALBECK, $\mathrm{H}$ : BRETLAU, $\mathrm{P}$ : HANSEN, $\mathrm{B}$ L et al Epstein-Barr virus infection in cultured nomalignant ephitelial cells from human nasopharyngeal mucosa. Arch. Otorrinolaryngol Chicago, v 246, p.142-146 1989.

2. AXELL, T;AZUL, AM; CHALLACOMBE, $S$ et al, Actualizaçāo da classificação e critérios diagnósticos das lesões orais na infecção pelo HIV Rev Port Est Cir Maxilofac Lisboa, v 34. n. 1 . 5-9 1993

3. DUTRA, M E P: COSTA C : FERREIRA, ET T et al Achados clínicos de interesse estomatológico em pacientes portadores da sindrome de imunodeficiência adquirida - AIDS Odonto, Sāo Paulo, v 2 , n 6, p 391-395, 1993.

4. EPSTEIN, JB;SHERLOCK, C H ; WOLBER, R A. et al. Hairy leukoplakia after bone marrow transplantation Oral Surg Oral Med. Oral Pathol, St Louis, v 75 n 6, p 690-695 1993.

5. EVERSOLE, LR; JACOBSEN, P ; STONE, CE etal. Oral condyloma planus (hairy leukoplakia) among homossexual men; a clinicopathologic study of thirty-six cases Oral Surg. Oral Med. Oral Pathol, St Louis, v61, p 249-255. 1986

6 FRIEDMAN-KEIN, AE Viral origin of hairy leukoplakia Lancet, London, v 2 p 694-695 1986

7. GREENSPAN D: GREENSPAN J S C CONANT $M$. et al. Oral "hairy" leukoplakia in male homossexuals: evidence of association with both papillomavirus and herpes-group virus. Lancet London, v 2, p 831-834 1984

8. GREENSPAN, D; GREENSPAN, J Significance of oral hairy leukoplakia. Oral Surg. Oral Med. Oral Pathol, St Louis, v.73, n 2, p 151-154, feb 1992

9 ITIN PH LALIENSCHLAGER S - FLUCKIGER, $R$ et al Oral manifestation in HiV - infected patients: diagnosis and management J Am Acad Dermalol, St Louis, v 29, n 5, p.749760 nov 1993

10 ITIN P.H Oral hairy leukoplakia Oral Surg Oral Med Oral Pathol, St Louis, v 73, n 2, p.151154, feb 1992

11. NAHER $H$ GISMANN $L$ : VONKNEBEL DOEBERITZ, $C$ el al Detection of EpsteinBarr virus - DNA in longue epithelium of human immunodeficiency virus - infected patients J Invest Dermatol New York v 97, 421-424. 1991

12. PINDBORG, J J Classification of oral lesions associaled with HIV infection. Oral Surg. Oral Med. Oral Pathol. St. Louis, v 67, p. 292-295. 1989

13. RAMIREZ V GONZÁLEZ A GONZÁLEZ $M$ et al Patologia bucal en 161 pacientes $\mathrm{VIH}$-positivos asintomáticos y sintomáticos. Rev. Inv. Clín, México, v 44, n 1, p 43-52, enero/marzo 1992

14. REGEZI Joseph SCIUBBA James Patologia bucal: correlaçōes clinicopatológicas. Rio de Janeiro: Guanabara Koogan, 1991. 390p Cap 3 Lesōes brancas p 67-69

15 SCHMIDT-WESTHAUSEN A. GEIDER BLOM $H R$. HETZER, $R$ et al Demonstration of Epstein-Barr virus in scrape material of lateral border of tongue in heart transplant patients by negative staining electron microscopy J Oral. Pathol Med Copenhagen, v.20, p 215-217 1991

16. SCIUBBA, $\mathrm{J}$; BRANSMA $\mathrm{J}$ : SCHWARTZ, $M$ et al Hairy leukoplakia: an AIDS - associated opportunistic infection. Oral Surg. Oral Med Oral Pathol., St Louis, v 67, p 404-410, 1989

17. SCULLY Crispian; ALMEIDA Oslei Paes de $\mathrm{BOZZO}$, Lourenço et al. Atlas de diagnóstico bucal São Paulo Santos, 1992 147p.

18 SNIDJERS, P JE; SCHULTEN, EAJM MULLINK, $H$, el al. Detection of human papillomavirus and Epstein-Barr vírus DNA sequences in oral mucosa of HIV - infected palients by polymerase chain reaction Am J Pathol, Philadelphia, v.137, p.659-666. 1990

19. SILVERMAN, JR, SOL Allas colorido das maniestacões bucais da AIDS Sảo Paulo: Santos 1989 113p Cap 4 Infecçōes virais p 40-47. 